\title{
USE OF GLUTARIC ACID TO IMPROVE THE SOLUBILITY AND DISSOLUTION PROFILE OF GLIPIZIDE THROUGH PHARMACEUTICAL COCRYSTALLIZATION
}

\author{
FAKHRA BATOOL, MAHMOOD AHMAD*, MUHAMMAD USMAN MINHAS, \\ FAHAD MEHMOOD KHAN, HAFIZ ARFAT IDREES and QANDEEL KHALID
}

Faculty of Pharmacy and Alternative Medicine, The Islamia University of Bahawalpur-63100, Punjab, Pakistan

\begin{abstract}
The purpose of current study was to improve the solubility and dissolution profile of BCS class-II drug Glipizide using glutaric acid as a coformer via various cocrystallization techniques i.e., dry grinding, liquid-assisted grinding, slurry, and solvent evaporation. Fourier Transform Infrared Spectroscopy (FTIR) was performed to determine the interaction between components of glipizide-glutaric acid (GPZ-GLU) cocrystals. Powder X-ray Diffraction (PXRD) studies confirmed the crystalline nature of formulated cocrystals. Scanning Electron Microscopy (SEM) revealed cylindrical to rectangular shape of cocrystals. Flow properties of GPZGLU cocrystals were evaluated by micromeritics analysis. Size and surface morphology was determined by zeta sizer analysis and optical microscopy. Differential scanning calorimetry (DSC) and Thermogravimetric (TGA) analysis were performed to determine the melting points as well as thermal stability of pure components and formulated GPZ-GLU cocrystals. In vitro drug release studies were carried out using dissolution apparatusII. GPZ-GLU cocrystals showed higher drug release at $\mathrm{pH} 6.8$ as compared to $\mathrm{pH}$ 1.2. However, percent drug release of optimum formulations at $\mathrm{pH} 6.8$ was determined as; $24-92.2 \%$ (F3) and 12.0-93.5\% (F7). Solubility studies revealed improved solubility as compared to the pure drug in water i.e., 53 folds and 54.27 folds from F3 and F7 cocrystals, respectively. Finally, it was concluded that glutaric acid has improved the solubility and dissolution profile of glipizide. However, many cocrystal formers have been reported in the literature that can be used to enhance the physicochemical properties as well as the bioavailability of poorly soluble drugs via cocrystallization technique.
\end{abstract}

Keywords: glipizide, glutaric acid, PXRD, SEM, FTIR, thermal analysis, solubility studies, in vitro drug release

Novelty statement: In this study pharmaceutical cocrystals of glipizide were prepared using glutaric acid as a coformer for solubility enhancement of glipizide by various cocrystallization techniques

Solubility is an important parameter to achieve the desired therapeutic concentration of drug within the body as it ultimately affects the pharmacological response of drug. Oral route of drug delivery is most convenient route however major problem in designing oral dosage forms is poor bioavailability mainly depends upon factors such as solubility, dissolution, permeability, and first-pass metabolism (1). In literature, various techniques have been reported such as micronization, cyclodextrin complexation, solid dispersions, floating granules, nanosuspension, solid lipid nanoparticles, supercritical fluid technology as well as pharmaceutical cocrystallization for solubility enhancement of poorly soluble drugs $(2,3)$.
Pharmaceutical cocrystals are molecular nonionic complexes used to enhance solubility, stability and ultimately bioavailability of active pharmaceutical ingredients without any change in API chemical properties. It is a crystalline solid consists of two components; one component is an active pharmaceutical ingredient and other is a cocrystal coformer. Coformer me be another drug or excipient. For the development of pharmaceutical Cocrystals, various methods have been employed including solid-state grinding, slurrying, liquid-assisted grinding and high throughput crystallization (4).

Glipizide is used for type 2 diabetes mellitus belongs to the class of second-generation sulphony-

\footnotetext{
* Corresponding author: e-mail: ma786_786@yahoo.com
} 
lureas. Being a BCS class-II drug it is practically insoluble in water according to British Pharmacopeia (BP). It needs to be administered in 2-3 doses of 2.5 $\mathrm{mg}$ to $10 \mathrm{mg}$ per day as it has a very short half life of $3.4 \pm 0.7 \mathrm{~h}(5,6)$. Glutaric acid is an organic acid that being a linear dicarboxylic acid can form hydrogen bond with various compounds and helps in their solubility enhancement. However, in previous literature, various other cocrystal formers have been reported such as tartaric acid, nicotinamide, glycolic acid and glutaric acid etc (7).

The purpose of the current study was to enhance the solubility and dissolution profile of glipizide by cocrystallization technique using glutaric acid as a coformer. Various reported techniques have been utilized for the fabrication of glipizide-glutaric acid cocrystals. Characterization was carried out by FTIR, SEM, PXRD, micromeritics, zeta sizer, optical microscopy, thermal analysis, solubility, and in vitro drug release studies.

\section{MATERIALS AND METHODOLOGY}

\section{Materials}

Glutaric acid was purchased from Sigma Aldrich, Germany. Glipizide was obtained as a gift from SUPRA chemicals, India. Sodium hydroxide $(\mathrm{NaOH})$ was purchased from Sigma Aldrich, Netherlands. Methanol, $\mathrm{HCl}, \mathrm{KCl}$, and potassium dihydrogen phosphate $\left(\mathrm{KH}_{2} \mathrm{PO}_{4}\right)$ were purchased from Merck, Germany. All other chemicals that were used during research work were of high quality and standards.

\section{Methodology}

Glipizide-Glutaric acid (GPZ-GLU) cocrystals were fabricated by previously reported methods such as Dry grinding, liquid-assisted grinding, slur- ry, and solvent evaporation. Drug \& coformer were taken together in stoichiometric amounts and ground using mortar and pestle for $60 \mathrm{~min}$ in case of solidstate grinding. Finally sieved to obtain the equal sized crystals (8). However, in the case of liquid assisted grinding active pharmaceutical ingredient and coformer were ground together by using a small amount of methanol for $30 \mathrm{~min}$, sieved and stored for further characterization (9). In the case of Slurry technique, equimolar amounts of coformer and drug were taken together and slurried at 250rpm overnight. The solution was allowed to evaporate slowly for $48 \mathrm{~h}$ at room temperature. The resulting solid was filtered, washed, dried, sieved and stored for further evaluation $(8,9)$. In Solvent evaporation (also known as solution crystallization) components were taken together in a stoichiometric ratio and solubilized in a common solvent. The solution was allowed to evaporate slowly at room temperature and resulted solid was dried, sieved and stored. This technique involves hydrogen bond formation between drug and coformer $(8,10)$.

Total eight numbers of formulations were prepared using different ratios of drug and glutaric acid. Composition of GPZ-GLU Cocrystals is shown in Table 1.

\section{CHARACTERIZATION}

\section{Fourier Transform Infrared Spectroscopic (FTIR) analysis}

FTIR spectra of individual components and synthesized cocrystals were taken using FTIR (Bruker Tenser 27, Germany with OPUS software) in the range of $1000 \mathrm{~cm}^{-1}$ to $3500 \mathrm{~cm}^{-1}$ with resolution power of $4 \mathrm{~cm}^{-1}$. It is used for the determination of interaction between formulation component; based on the principle that chemical bonds absorb

Table 1. Composition of GPZ-GLU cocrystals.

\begin{tabular}{|c|c|c|c|c|c|}
\hline Method & Formulation & Ratio & Glipizide & Glutaric acid & Methanol \\
\hline \multirow{3}{*}{ Dry grinding } & F1 & $1: 1$ & 2.3 & 0.66 & 1.32 \\
\cline { 2 - 6 } & F5 & $1: 2$ & 2.3 & 0.66 & $1-2 \mathrm{~mL}$ \\
\hline \multirow{2}{*}{ LAG } & F2 & $1: 1$ & 2.3 & 1.32 & $1-2 \mathrm{~mL}$ \\
\hline \multirow{2}{*}{ Slurry } & F6 & $1: 2$ & 2.3 & 0.66 & $8-15 \mathrm{~mL}$ \\
\cline { 2 - 6 } & F3 & $1: 1$ & 2.3 & 1.32 & $8-15 \mathrm{~mL}$ \\
\hline Solvent & F7 & $1: 2$ & 2.3 & 0.66 & $5-8 \mathrm{~mL}$ \\
\cline { 2 - 6 } & F4 & $1: 1$ & 2.3 & 1.32 & $5-8 \mathrm{~mL}$ \\
\hline
\end{tabular}

Note: Weight of the ingredients was taken in grams equivalent to $5 \mathrm{mmol}$ each 
infrared light and get excited at frequencies that are typical for the particular types of the chemical bonds (11).

\section{Powder X-Ray Diffraction (PXRD) studies}

$\mathrm{X}$-ray diffraction studies were performed to determine the crystalline or amorphous nature of a substance. It gives a unique 'fingerprint' diffraction pattern (12). Bruker D8 Advance diffractometer (Germany) was used for this purpose under the given conditions of Voltage $=40 \mathrm{KV}$, Current $=40$ $\mathrm{mA}$, and $2 \theta$ value in the range of $5-70^{\circ}$. The X-rays Diffraction pattern of API and cocrystals was determined and compared with API.

\section{Scanning Electron Microscopy (SEM)}

Surface morphology of GPZ-GLU Cocrystals was determined by (Zeiss EVO LS 10, Carl Zeiss Microscopy GmbH) Scanning Electron microscope. To reduce thermal degradation as well as to improve the electron emission cocrystals were coated by sputtered atoms in the form of gold for $10 \mathrm{~min}$. Shape and surface morphology was evaluated by scanning of cocrystals and recording their photomicrographs.

\section{Micromeritics properties}

Angle of repose was determined by Fixed funnel method in which powdered formulation was poured through glass funnel by placing the Petri dish below the funnel. A value of angle of repose less than $30^{\circ}$ indicates good flow properties $(13,14)$. Equation 1 was used for calculation of the angle of repose;

$$
\operatorname{Tan} \theta=\frac{h}{r}
$$

$(\theta=$ angle of repose, $h=$ height of heap, $r=$ radius of the base)

Bulk density was calculated using the Equation 2. Bulk volume was visually noted by pouring powder mixture into a graduated measuring cylinder (13).

$$
\text { Bulk density }(p b)=\frac{M}{V b}
$$

( $\mathrm{M}=$ Mass of powder, $\mathrm{Vb}=$ Bulk volume)

Tapped density was calculated by Equation 3 (14). Tapped volume was noted by placing a known mass of cocrystals into measuring cylinder and tapped for, specified number of tappings.

$$
\text { Tapped density }(p b)=\frac{M}{V t}
$$

( $\mathrm{M}=$ Mass of powder, $\mathrm{Vt}=$ Tapped volume $)$

Carr's compressibility index was calculated by using Equation 4. A value of Carr's index (I) between 13-19\% indicates good flow property while value $>21 \%$ shows poor flow property (14).
Compressibility index $(\mathrm{I})=\frac{V b-V t}{V b} \times 100$

( $\mathrm{Vb}=$ Bulk volume, $\mathrm{Vt}=$ Tapped volume $)$

Hausner ratio less than 1.25 indicates good flow property (13) and it was calculated by Equation 5:

$$
\begin{gathered}
\text { Hausner ratio }=\frac{\rho t}{\rho b} \\
(\rho \mathrm{t}=\text { Tapped density, } \rho \mathrm{b}=\text { Bulk density })
\end{gathered}
$$

\section{Optical microscopy}

Size, as well as the morphology of GPZ-GLU cocrystals, was determined by Optical microscope (Nikon E200, Tokyo, Japan) equipped with (DCM35 USB 2.0 and MINISEE IMAGE software, Scopetek Electric, Hangzhou, China).

\section{Zeta sizer}

Particle size of formulated cocrystals was confirmed by single particle size analyzer using Zetasizer Nano-series ZEN3600, Malvern instruments Ltd. with software DTS-nano. Information about size and size distribution can be obtained by peak area, peak number and peak amplitude (15).

\section{Thermal analysis}

Differential Scanning Calorimetry (DSC) is useful in detecting phase changes that do not result in a change of polymorphic transitions. DSC gives an accurate value for melting onset temperature while Thermogravimetric analysis (TGA) records sample weight loss during heating usually at a constant rate. For this purpose, SDT Q 600 Series Thermal Analysis System (TA Instruments, USA) was used in the range of $0-500^{\circ} \mathrm{C}$ by maintaining heat at $10^{\circ} \mathrm{C} / \mathrm{min}$ with a flow rate of 10 $\mathrm{mL} / \mathrm{min}$. Thermal analysis of GPZ-GLU cocrystals and pure components was determined.

\section{In vitro dissolution studies}

In vitro studies were carried using USP dissolution apparatus II at both acidic and basic $\mathrm{pH}$ i.e., 1.2 and 6.8 respectively. For each basket $900 \mathrm{~mL}$ volume of dissolution media was taken. After maintaining the proper sink conditions, apparatus was operated at $50 \mathrm{rpm}$ at room temperature (37 \pm $0.5^{\circ} \mathrm{C}$ ). Using pipette $5 \mathrm{~mL}$ samples were taken (at different time intervals i.e., $0,10,15,30,45,60,90$, \& $120 \mathrm{~min}$ ), filtered, diluted and analyzed by UVVisible spectrophotometer at $\lambda \max$ of $276 \mathrm{~nm}$. Each time volume was replaced with fresh dissolution medium and all readings were taken in triplicate.

\section{Solubility studies}

An excess amount of GPZ and GPZ-GLU cocrystals was added to $10 \mathrm{~mL}$ of different solutions 


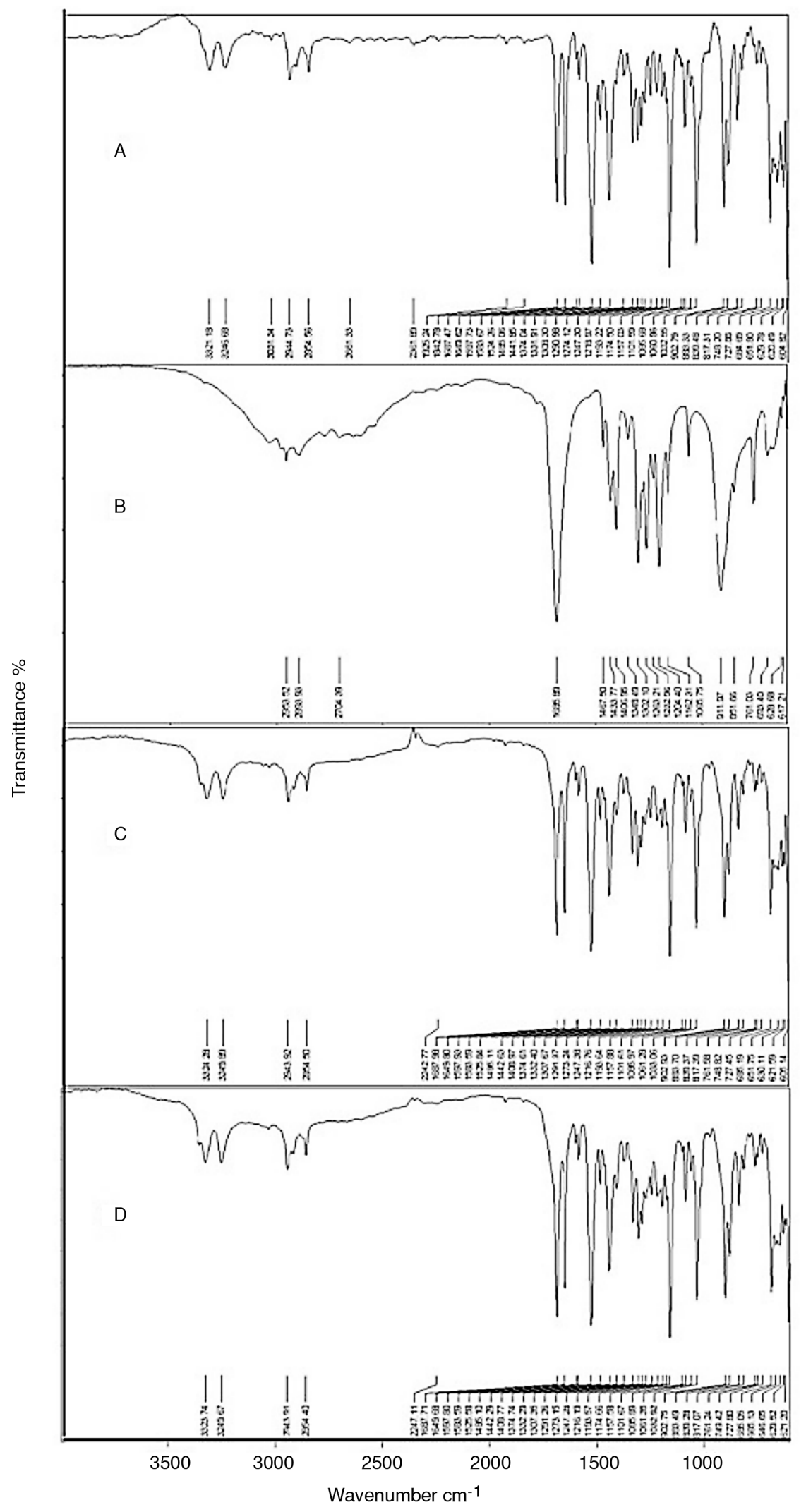

Figure 1. FTIR spectra of (A) GPZ, (B) GLU, (C) F3-Cocrystals, (D) F7-Cocrystals 


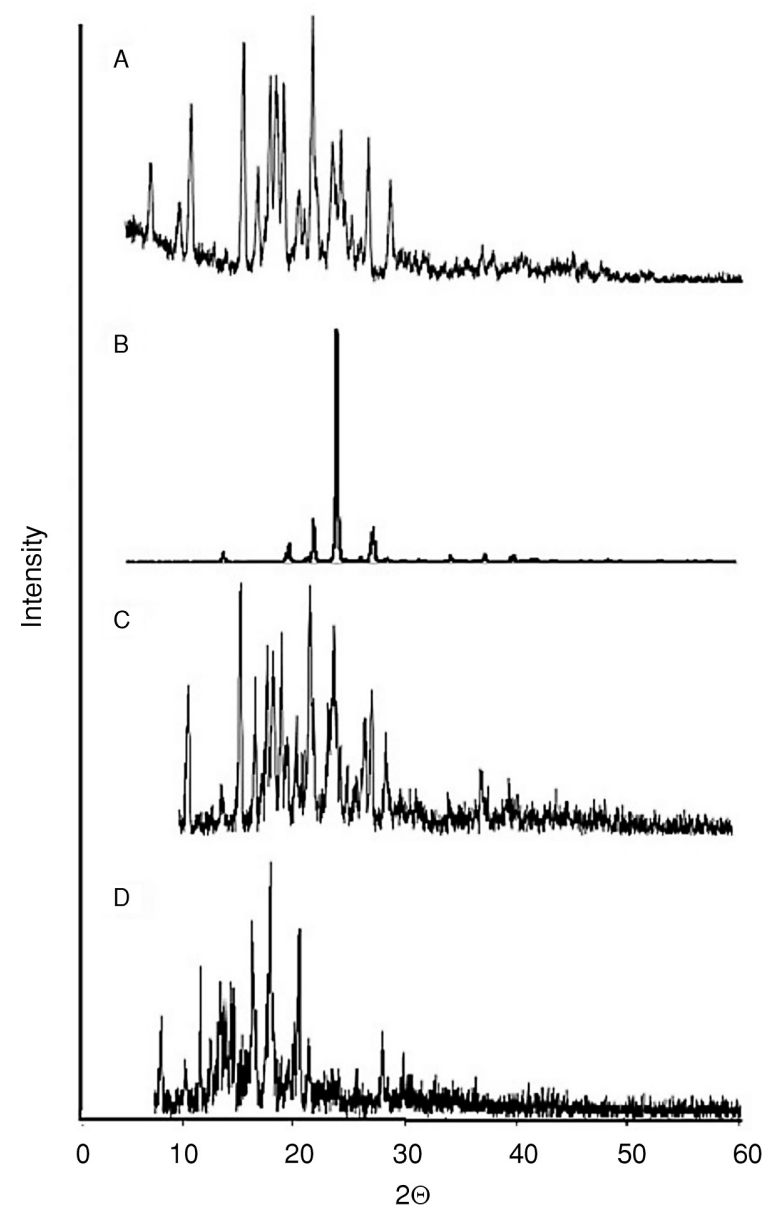

Figure 2. X-ray Diffractogram A) Glipizide, B) Glutaric acid, C) GPZ-GLU (1:1) cocrystal (F3), D) GPZ-GLU (1:2) Cocrystals (F7)

such as water, $\mathrm{pH} 1.2$ buffer and $\mathrm{pH} 6.8$ buffer separately, in screw-capped glass vials wrapped with aluminum foil to protect from light. Vials were subjected to mechanical shaking at $400 \mathrm{rpm}$ for $24 \mathrm{~h}$ using magnetic stirrer. Whatman paper no. 42 was used for sample filtration. The supernatant was suitably diluted and analyzed at $\lambda$ max of $276 \mathrm{~nm}$ using UV-visible spectrophotometer (5). Measurements were taken in triplicate.

\section{RESULTS AND DISCUSSION}

\section{Fourier Transform Infrared Spectroscopy}

FTIR spectra of pure glipizide, Glutaric acid and formulated GPZ-GLU cocrystals were examined in the range of 1000 to $3500 \mathrm{~cm}^{-1}$ to identify the physical and chemical interactions. Glipizide showed a prominent band at $1649.62 \mathrm{~cm}^{-1}$ due to the presence of $-\mathrm{C}=\mathrm{N}$ aliphatic group. Band at 2944.73 $\mathrm{cm}^{-1}$ indicates $-\mathrm{CH} 2$ aliphatic group. N-H stretching band of-NH2 group appeared at $3321.18 \mathrm{~cm}^{-1}$. band at $1524.26 \mathrm{~cm}^{-1}, 1308.30 \mathrm{~cm}^{-1}$, and at $839.48 \mathrm{~cm}^{-1}$ was observed due to $\mathrm{C}-\mathrm{H}$ stretching, $\mathrm{C}-\mathrm{C}$ stretching and $\mathrm{S}=\mathrm{O}$ stretching respectively. Similarly $-\mathrm{C}=\mathrm{O}$ stretching band was observed at $1687.47 \mathrm{~cm}^{-1}$ (1618).

Glutaric acid is an organic acid that being a linear dicarboxylic acid it can form hydrogen bond with various compounds and helps in their solubility enhancement. Carboxylic acids show strong stretching bond of $\mathrm{O}-\mathrm{H}$ group at $3300-2500 \mathrm{~cm}^{-1}$. While $\mathrm{C}=\mathrm{O}$ stretching bond, free acid band and $\mathrm{C}-\mathrm{O}$ stretching at $1700 \mathrm{~cm}^{-1}, 1760 \mathrm{~cm}^{-1}$ and $1240 \mathrm{~cm}^{-1}$ respectively. Similarly, O-H in-plane and out of plane bending is observed at $1430 \mathrm{~cm}^{-1}$ and $930 \mathrm{~cm}^{-1}$ respectively (19). FTIR spectra of Glutaric acid represented the prominent band at $2893.93 \mathrm{~cm}^{-1}$ and $2953.52 \mathrm{~cm}^{-1}$ indicating the presence of $-\mathrm{OH}$ group. 
A sharp and deep band due to $\mathrm{C}=\mathrm{O}$ stretching and -C-O group was observed at $1685.89 \mathrm{~cm}^{-1}$ and $1232.96 \mathrm{~cm}^{-1}$, respectively. While $\mathrm{O}-\mathrm{H}$ in-plane and out of plane bending was observed at $1433.77 \mathrm{~cm}^{-1}$ and $911.97 \mathrm{~cm}^{-1}$, respectively.

In the case of GPZ-GLU (1:1) cocrystals, all the band of the drug was present indicating the drug stability within the formulated cocrystals. However, a new band was appeared at $2242.77 \mathrm{~cm}^{-1}$ possibly due to the formation of H-bond. Similarly in GPZGLU (1:2) cocrystals band at $2242.77 \mathrm{~cm}^{-1}$ was also observed along with all drug peaks indicating glipizide stability in cocrystals. FTIR spectra of pure components and GPZ-GLU cocrystals have presented in Figure 1.

\section{Powder X-ray diffractometer analysis}

To determine the nature of pharmaceutical cocrystals, X-ray diffraction studies were performed. PXRD provides evidence of complexation or interaction. Glipizide showed sharp and intense peaks at $2 \theta$ $=7.48^{\circ}, 10.00^{\circ}, 11.08^{\circ}, 15.72^{\circ}, 16.67^{\circ}, 18.67^{\circ}$,

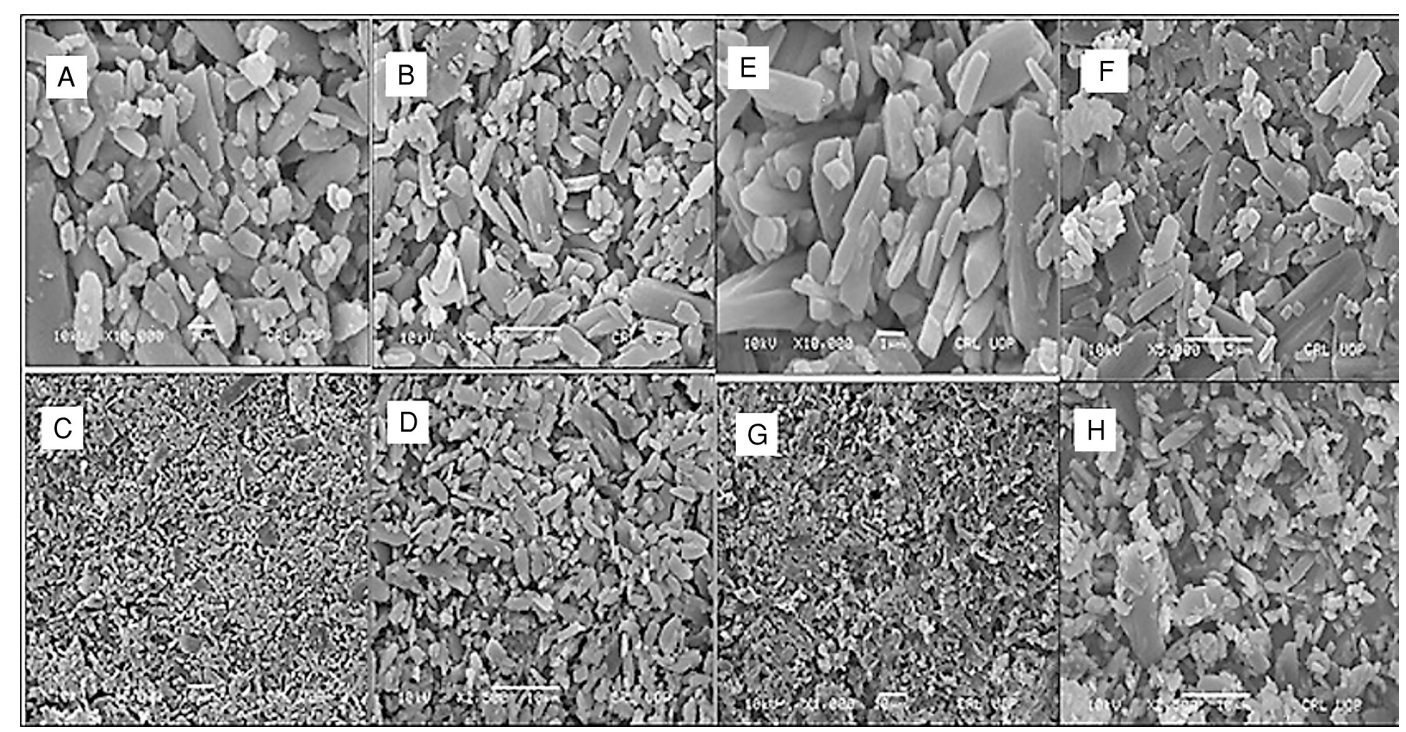

Figure 3. SEM Micrographs of F3 Cocrystals (A, B, C, D) and F7 cocrystals (E, F, G, H) at different scale bars, respectively

Table 2. Micromeritic properties of GPZ-GLU Cocrystals (Mean \pm SD) $(n=3)$.

\begin{tabular}{|c|c|c|c|c|c|}
\hline Formulations & $\begin{array}{c}\text { Bulk density } \\
\mathrm{g} / \mathrm{mL}\end{array}$ & $\begin{array}{c}\text { Tapped density } \\
\mathrm{g} / \mathrm{mL}\end{array}$ & $\begin{array}{c}\text { Hausner's } \\
\text { Ratio }\end{array}$ & $\begin{array}{c}\text { Carr's index } \\
(\%)\end{array}$ & $\begin{array}{c}\text { Angle of repose } \\
\left({ }^{\circ}\right)\end{array}$ \\
\hline F1 & $0.42 \pm 0.05$ & $0.48 \pm 0.031$ & $1.15 \pm 0.035$ & $13.6 \pm 0.051$ & $13.17 \pm 0.025$ \\
\hline F2 & $0.35 \pm 0.030$ & $0.42 \pm 0.023$ & $1.12 \pm 0.051$ & $16.7 \pm 0.042$ & $14.19 \pm 0.051$ \\
\hline F3 & $0.31 \pm 0.021$ & $0.37 \pm 0.025$ & $1.17 \pm 0.023$ & $15.0 \pm 0.016$ & $11.31 \pm 0.060$ \\
\hline F4 & $0.37 \pm 0.018$ & $0.46 \pm 0.005$ & $1.23 \pm 0.006$ & $18.75 \pm 0.041$ & $11.88 \pm 0.017$ \\
\hline F5 & $1.43 \pm 0.050$ & $1.87 \pm 0.020$ & $1.23 \pm 0.023$ & $18.7 \pm 0.050$ & $13.04 \pm 0.007$ \\
\hline F6 & $0.90 \pm 0.022$ & $1.04 \pm 0.050$ & $1.15 \pm 0.005$ & $13.33 \pm 0.015$ & $9.54 \pm 0.025$ \\
\hline F7 & $0.30 \pm 0.030$ & $0.33 \pm 0.070$ & $1.10 \pm 0.018$ & $9.37 \pm 0.060$ & $20.76 \pm 0.017$ \\
\hline F8 & $0.35 \pm 0.040$ & $0.36 \pm 0.030$ & $1.23 \pm 0.051$ & $18.57 \pm 0.070$ & $15.31 \pm 0.007$ \\
\hline
\end{tabular}

Table 3. Particle size and Polydispersity index (PDI) of GPZ-GLU cocrystals.

\begin{tabular}{|c|c|c|}
\hline Formulation & Average particle size \pm SD $(\mathrm{nm})$ & Polydispersity index (PDI) \\
\hline Glip-GLU & $3213 \pm 104.0$ & 0.828 \\
\hline
\end{tabular}




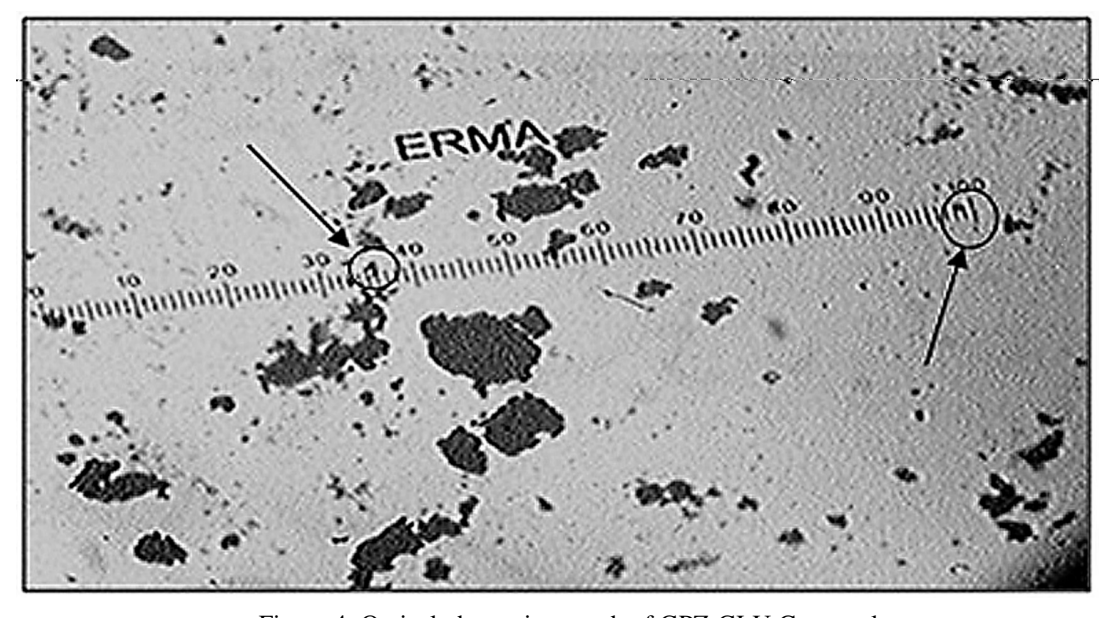

Figure 4. Optical photomicrograph of GPZ-GLU Cocrystals

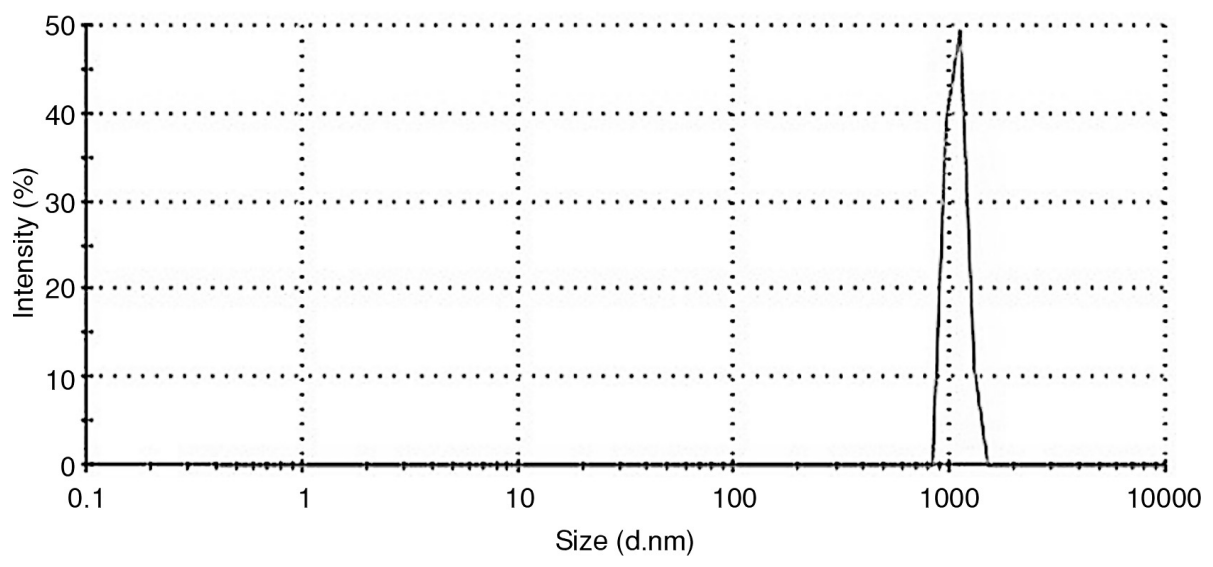

Figure 5. Zeta sizer analysis of GPZ-GLU cocrystals

$21.86^{\circ}, 23.90^{\circ}, 26.42^{\circ}$ and $28.00^{\circ}$, indicating its highly crystalline nature $(20,21)$. Pure glutaric acid showed sharp and prominent peaks at $2 \theta=14^{\circ}, 19.8^{\circ}$, $22^{\circ}, 24^{\circ}$ (very sharp peak) and $27^{\circ}$ indicating the crystalline nature of glutaric acid. Formulated GPZ-GLU (1:1) cocrystals showed crystalline peaks at different $2 \theta$ values. However, peaks are diffused as compared to the XRD pattern of pure components indicating the change in the crystalline nature of components into semicrystalline. Similarly, in the case of GPZ-GLU $(1: 2)$ cocrystals, crystalline peaks were present indicating the formation of cocrystals. All the crystalline peaks of glipizide were seen in formulated cocrystals as supported by a previous study (22). PXRD pattern of pure components and fabricated GPZ-GLU cocrystals has given in Figure 2.

\section{Scanning Electron Microscopy}

SEM studies were performed at different scale bars i.e., $1 \mu \mathrm{m}, 5 \mu \mathrm{m}$ and $10 \mu \mathrm{m}$ (with different resolution powers i.e. $1000 \mathrm{X}, 2500 \mathrm{X}, 5000 \mathrm{X}$, and $10,000 \mathrm{X})$. SEM images of GPZ-GLU (1:1) cocrystals showed cylindrical to rectangular shape of cocrystals with white to greyish appearance indicating the glipizide presence in cocrystals. Similar results were seen in case of the GPZ-GLU $(1: 2)$ cocrystals with an appearance of white colored drug steaks around the cocrystals with a smooth surface as shown in Figure 3.

\section{Micromeritics analysis}

Flow properties of Glip-Glutaric acid (GPZGLU) cocrystals were evaluated by Bulk Density, 

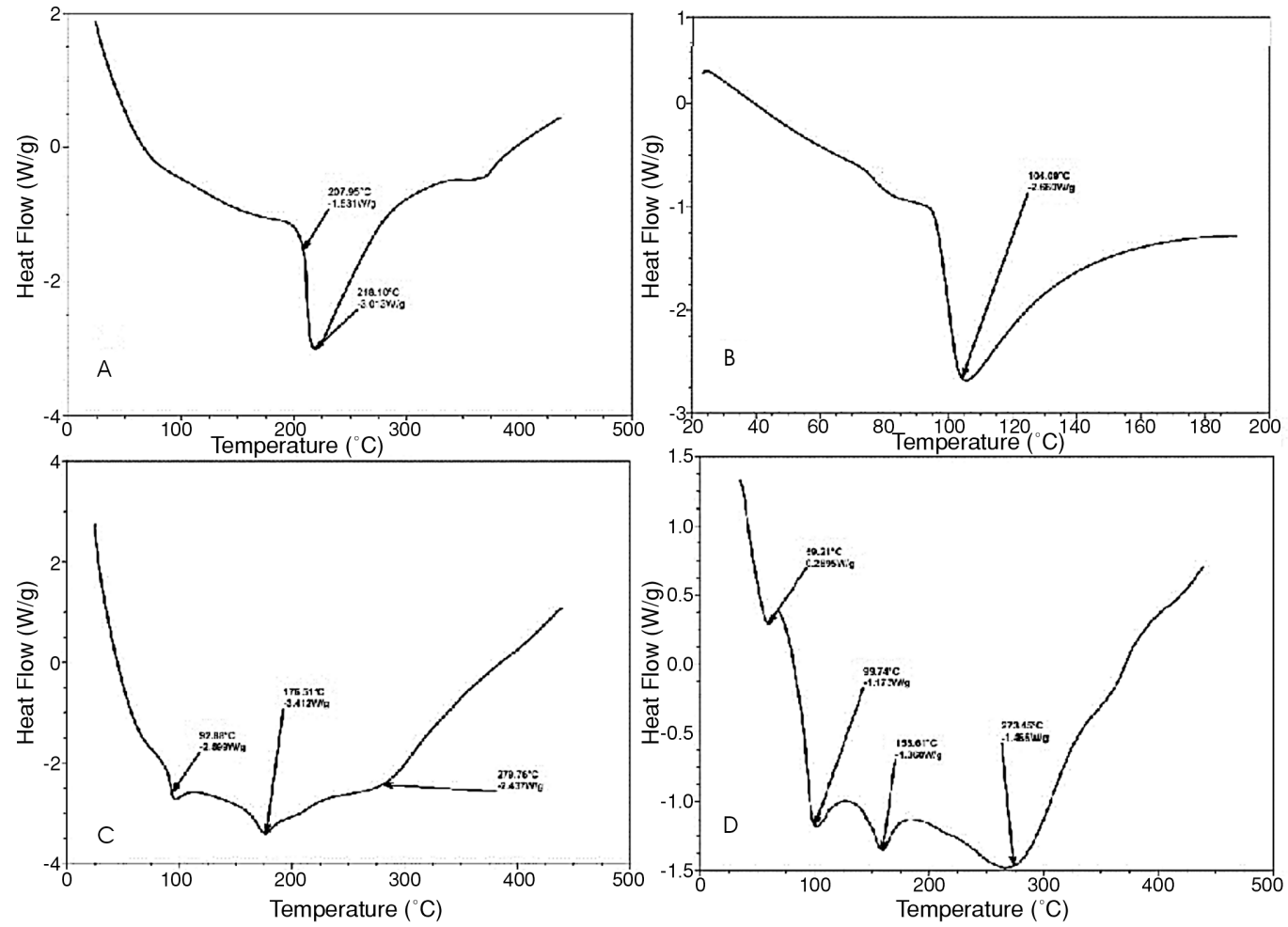

Figure 6. DSC curve of (A) GPZ, (B) GLU, (C) GPZ-GLU (1 : 1) cocrystals (F3), (D) GPZ-GLU (1:2) cocrystals (F7)
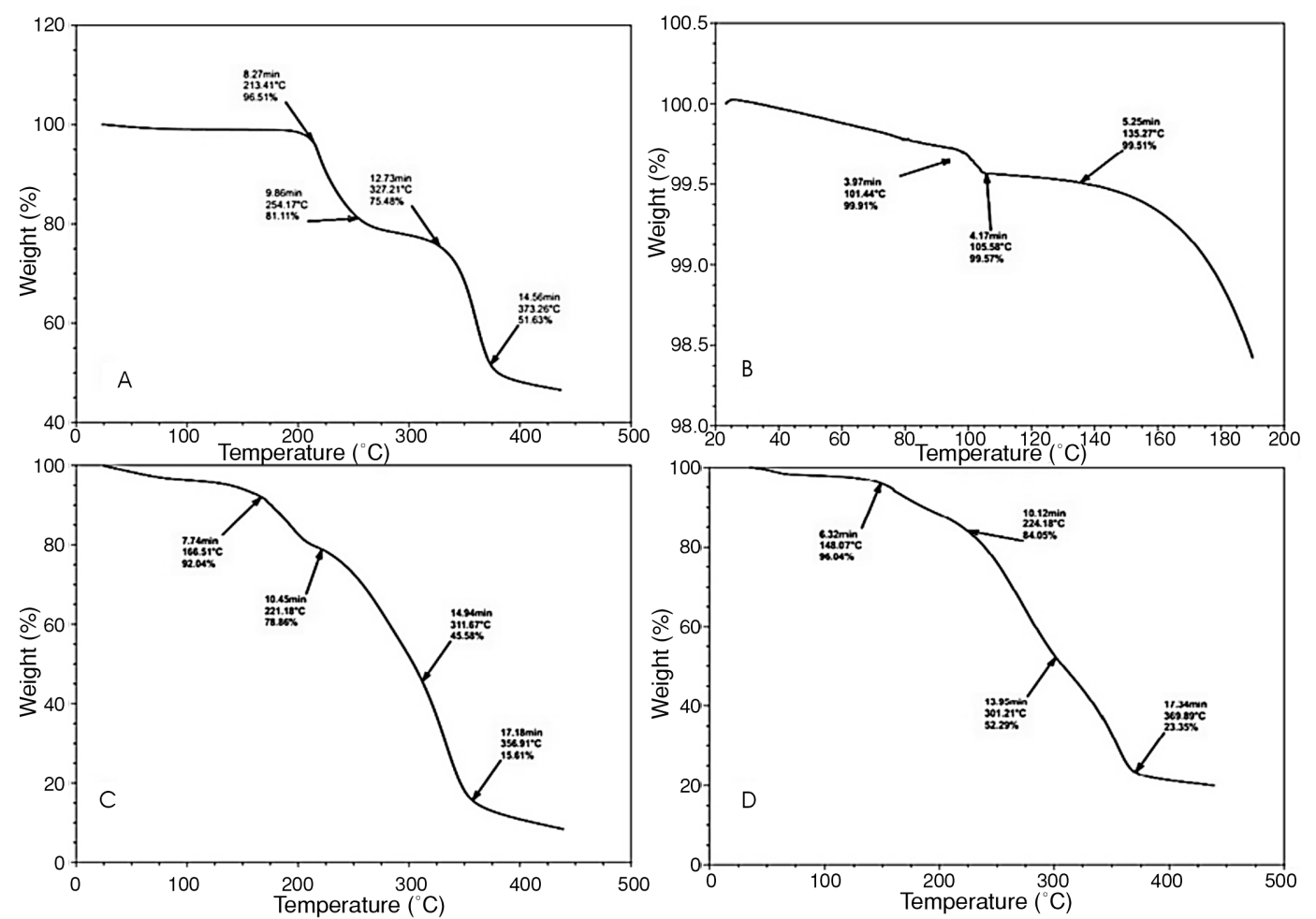

Figure 7. TGA thermogram of (A) GPZ, (B) GLU, (C) F3-cocrystals, (D) F7-cocrystals 
Tapped Density, Hausner Ratio, Carr's Compressibility Index and Angle of Repose. The angle of repose is related to interparticle cohesion and indirectly determine the flow properties of powders (23). Angle of repose was found as F1 $\left(13.17^{\circ}\right), \mathrm{F} 2$ $\left(14.19^{\circ}\right)$, F3 $\left(11.31^{\circ}\right)$, F4 $\left(11.88^{\circ}\right)$, F5 $\left(13.04^{\circ}\right)$, F6 $\left(9.54^{\circ}\right), \mathrm{F} 7\left(20.76^{\circ}\right)$ and for F8 $\left(15.31^{\circ}\right)$. The bulk densities for GPZ-GLU $(1: 1)$ and GPZ-GLU $(1: 2)$ cocrystals were found in the range of $0.31-0.42$ $\mathrm{g} / \mathrm{mL}$ and $0.3-1.43 \mathrm{~g} / \mathrm{mL}$ respectively. Similarly, values for tapped densities were in the range of 0.37 $0.48 \mathrm{~g} / \mathrm{mL}$ and $0.33-1.9 \mathrm{~g} / \mathrm{mL}$ for GPZ-GLU (1: 1) and GPZ-GLU (1:2) cocrystals, respectively.

The lower value of bulk densities represents porosity within the cocrystals however bulk and tapped density are the parameters that assess packability of powders (24). Hausner's ratio was found in the range of 1.15-1.23 for GPZ-GLU (1:1) cocrystals and 1.10-1.23 for GPZ-GLU $(1: 2)$ cocrystals. However, values approximate to 1.2 indicate good flow properties as reported in various studies (25). Carr's compressibility index was found as 13.6$18.7 \%$ for GPZ-GLU (1: 1) cocrystals and 9.4$18.7 \%$ for GPZ-GLU (1: 2) cocrystals. In reported studies, a value of 5-15\% indicate the excellent flow properties. However, a value of $12-16 \%$ and $18-21 \%$ showed very good and good flow behaviors respectively $(26,27)$. Results of micromeritics properties have summarized in Table 2.

\section{Optical microscopy}

GPZ-GLU cocrystals were found in the micrometric to nanometric range $(1 \mu \mathrm{m}-1000 \mathrm{~nm})$ as confirmed by optical microscope (Nikon E200, Tokyo, Japan). Optical microscope revealed a non-uniform appearance of GPZ-GLU cocrystals as shown in Figure 4.

\section{Zeta sizer analysis}

The particle size analysis of GPZ-GLU cocrystals revealed average particle size (Z-average) was $3213 \mathrm{~nm}$ with a polydispersity index (PDI) of 0.828 as shown in Figure 5 and Table 3. PDI value $=0.1$ indicate monodispersity and PDI $>0.1$ show polydispersity. PDI represents particle size distribution. Reduction in particle size offers a large surface area thereby improves solubility, dissolution, and bioavailability of poorly soluble drugs (28).

\section{Differential Scanning Calorimetery and Thermo gravimetric analysis}

Differential Scanning Calorimetry (DSC) and Thermogravimetric analysis (TGA) were carried out in the range of $0-500^{\circ} \mathrm{C}$ to determine the phase transitions and percent mass loss with increasing temperature. DSC curve of pure Glipizide presented a deep and sharp endothermic peak at $218.10^{\circ} \mathrm{C}$ with a Heat flow of $-3.013 \mathrm{~W} / \mathrm{g}$, indicating the melting point of drug $(29,30)$. TGA thermogram of pure Glipizide showed the first mass loss of $3.49 \%$ at $213.41^{\circ} \mathrm{C}$ after 8.27 min. Second mass loss was $18.89 \%$ at $254.17^{\circ} \mathrm{C}$ after 9.86 min. Maximum mass loss $48.37 \%$ was observed at $373.26^{\circ} \mathrm{C}$ after $14.56 \mathrm{~min}$. Thermal analysis of Glutaric acid was carried out in the range of $0-200^{\circ} \mathrm{C}$. Glutaric acid undergoes solid-solid phase transformation at $77.08^{\circ} \mathrm{C}$ with Heat flow of $-0.7456 \mathrm{~W} / \mathrm{g}$. A sharp endothermic peak representing melting temperature was observed at $104.09^{\circ} \mathrm{C}$ (Heat flow $=-2.660$ $\mathrm{W} / \mathrm{g}$ ). The results were supported by a study in which glutaric acid cocrystals were prepared to improve the oral bioavailability of poorly water soluble drug (31).

TGA thermogram of glutaric acid showed first mass loss i.e., $0.1 \%$ at $101.53^{\circ} \mathrm{C}$ after $3.97 \mathrm{~min}$ and maximum weight loss was observed at $162.50^{\circ} \mathrm{C}$ after $6.28 \mathrm{~min}$ as $0.7 \%$.
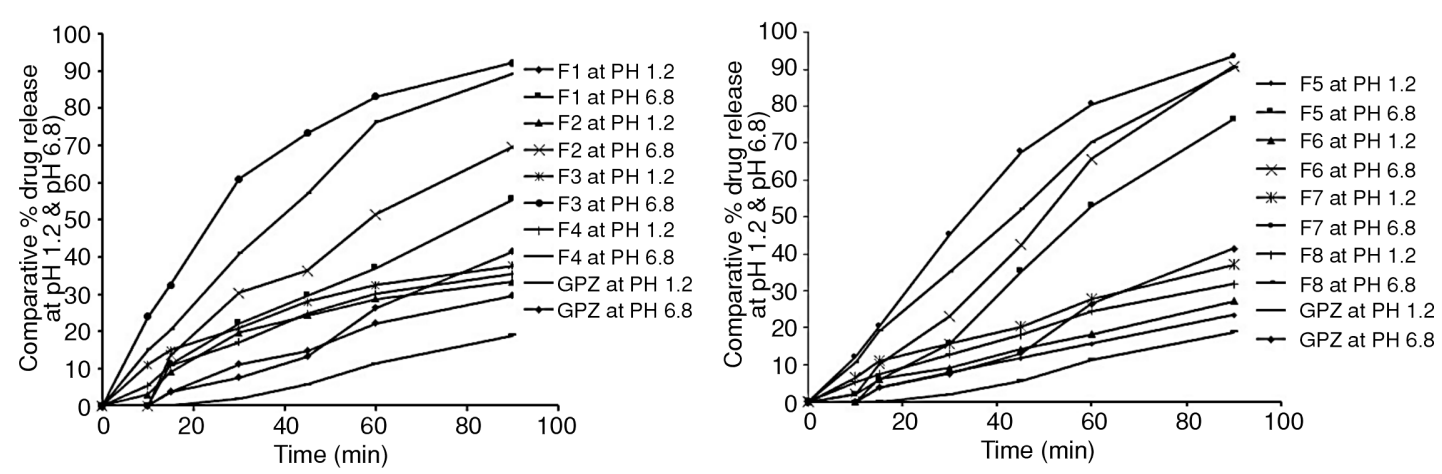

Figure 8. In-vitro release studies of (A) GPZ-GLU (1:1) cocrystals \& (B) GPZ-GLU (1:2) cocrystals at pH 1.2 and 6.8 
DSC curve of synthesized GPZ-GLU (1:1) cocrystals was recorded at $0-500^{\circ} \mathrm{C}$. It was observed that peak of glutaric acid at $77.08^{\circ} \mathrm{C}$ (Heat flow $=$ $-0.7456 \mathrm{~W} / \mathrm{g})$ was shifted to $92.88^{\circ} \mathrm{C}(\Delta \mathrm{H}=-2.599$ $\mathrm{W} / \mathrm{g})$. While deep endothermic peak at $104.09^{\circ} \mathrm{C}$ was shifted to $176.51^{\circ} \mathrm{C}(\Delta \mathrm{H}=-3.412 \mathrm{~W} / \mathrm{g})$ with reduced intensity. A new peak with reduced intensity was observed at $279.76^{\circ} \mathrm{C}(\Delta \mathrm{H}=-2.437 \mathrm{~W} / \mathrm{g})$. However, drug peak at $218^{\circ} \mathrm{C}$ was disappeared in formulated cocrystals indicating the interaction of the drug with glutaric acid. TGA thermogram of GPZ-GLU (1: 1) cocrystals showed maximum weight loss was $84.39 \%$ at $356.91^{\circ} \mathrm{C}$ after $17.18 \mathrm{~min}$. DSC thermogram of GPZ-GLU (1:2) cocrystals indicated a small endothermic peak at $59.21^{\circ} \mathrm{C}(\Delta \mathrm{H}=-0.2895 \mathrm{~W} / \mathrm{g})$. A small endothermic peak of glutaric acid at $77.08^{\circ} \mathrm{C}$ was shifted to $99.74^{\circ} \mathrm{C}$. New endothermic peaks were observed at $158.61^{\circ} \mathrm{C}$ and at $273.45^{\circ} \mathrm{C}$ indicating the formation of cocrystals. TGA thermogram of GPZ-GLU (1:2) corystals showed maximum weight loss i.e., $76.65 \%$ at $369.89^{\circ} \mathrm{C}$ after $17.34 \mathrm{~min}$. DSC curve and TGA thermogram of pure components and synthesized cocrystals are presented in Figure 6 and Figure 7 respectively.

\section{In vitro drug release studies}

Dissolution studies were carried out in triplicate at $37^{\circ} \mathrm{C}$ in $\mathrm{pH} 1.2$ and 6.8 buffer media to simulate gastric and intestinal conditions, respectively.
Dissolution studies were carried out for all GPZGLU cocrystals. GPZ-GLU (1:1) cocrystals showed higher drug release at $\mathrm{pH} 6.8$ as compared to $\mathrm{pH}$ 1.2. Being a weak acid $(\mathrm{pKa}=5.9)$ glipizide expected to have higher drug release $n$ basic media $(32,33)$. At $\mathrm{pH} 1.2$ percent drug release was found as i.e., F1 (3.7-37\%), F2 (3.0-37.8\%), F3 (11.0-43.5\%), F4 (5.3-40.8\%) and GPZ (1.88-32\%). However, percent drug release at $\mathrm{pH} 6.8$ was determined higher than at pH 1.2 as; $11.1-55.6 \%$ (F1), 13.6-69.7\% (F2), 24$92.2 \%(\mathrm{~F} 3), 15.1-89.2 \%(\mathrm{~F} 4)$ and $3.8-41.5 \%$ (GPZ).

F1 was the formulation prepared by dry grinding, F2 by liquid assisted grinding, F3 by slurry and F4 by solvent evaporation technique. The order of drug release from all formulations was found as;

F3 $>$ F4 $>$ F2 $>$ F1 > GPZ

Results of drug release depicted F3 formulation as the optimum formulation for further characterization due to higher drug release (24-92.2\%) at pH 6.8 as compared to other formulations. Glutaric acid being a carboxylic acid provides a site for $\mathrm{H}-$ bonding thereby improves dissolution profiles of poorly water-soluble drugs.

GPZ-GLU (1:2) cocrystals also showed higher drug release at $\mathrm{pH} 6.8$ than $\mathrm{pH} 1.2$. The drug release at $\mathrm{pH} 6.8$ was determined as; 1.96-76.4\% (F5-dry grinding), 2.0-90.2\% (F6-LAG), 12.0-93.5\% (F7slurry) and $10.6-90.4 \%$ (F8-solvent evaporation). Similarly cocrystals when evaluated for percent drug
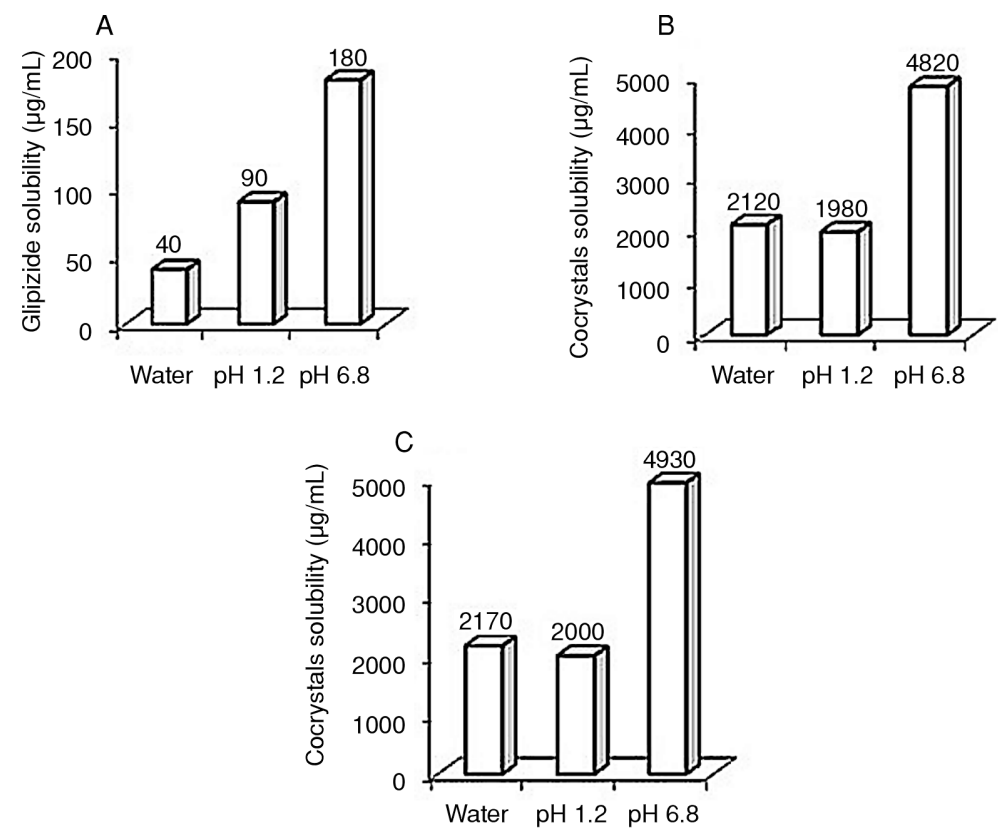

Figure 9. Solubility studies of (A) Glipizide, (B) F3 = Cocrystals, (C) F7 = Cocrystals 
release at $\mathrm{pH} 1.2$ the results were; $3.9-35.2 \%, 6.0$ $39.3 \%, 6.5-44 \%$ and $5.3-41.5 \%$ for F5, F6, F7 and F8, respectively. F7 prepared by slurry method was selected as optimum formulation owing to higher drug release (12.0-93.5\%) among all the formulations at $\mathrm{pH}$ 6.8. However, the order of in vitro release was: F7 > F8 F6 > F5 > GPZ >

The results were supported by various previously reported studies $(31,34)$. Comparative percent drug release from GPZ-GLU $(1: 1)$ and GPZ-GLU $(1: 2)$ cocrystals have shown in Figure 8 (A) and (B) respectively.

\section{Solubility studies}

Two optimum formulations were selected i.e., F3 from GPZ-GLU (1: 1) and F7 from GPZ-GLU $(1: 2)$ cocrystals for solubility studies. Solubility studies were carried out in $\mathrm{pH} 1.2$, pH 6.8 and water. A significant increase in solubility of drug as compared to pure drug was observed as shown in Figure 9. F3 cocrystals showed a significant increase in solubility in different media i.e., 53 folds in water, 22 folds in acidic buffer and 26.8 folds increase in basic media. However, F7 showed 54.27 folds, 22.22 folds and 27.39 folds higher solubility in water, acidic media ( $\mathrm{pH} 1.2)$ and in basic media ( $\mathrm{pH}$ 6.8), respectively as compared to pure drug. In a previous study solubility of glipizide in different solvents was determined and their results supported our findings (35). In literature, various studies have been reported that describe the solubility advantage of pharmaceutical cocrystals $(36,37)$.

\section{CONCLUSION}

The formulated GPZ-GLU cocrystals showed improved solubility and dissolution profile as compared to pure drug demonstrating the utility of cocrystallization technique for solubility enhancement of various poorly water-soluble drugs. In conclusion, we believe that along with the solubility and dissolution profile, bioavailability of GPZ as well as other BCS class-II drugs can be improved by the formation of pharmaceutical cocrystals.

\section{Acknowledgments}

The authors would like to acknowledge financial assistance from the Islamia University of Bahawalpur, Punjab- Pakistan.

\section{Declaration of interests}

The authors report no conflict of interests.

\section{REFERENCES}

1. Savjani K.T., Gajjar A.K., Savjani J.K.: ISRN Pharm. (2012).

2. Kumar A., Sahoo S.K., Padhee K., Kochar P., Sathapathy A., Pathak N.: Pharmacie Globale 3, 3 (2011).

3. Krishnaiah Y.S.: J. Bioequiv. Availab. 2 (2010).

4. Sekhon B.S.: ARS Pharm. 50 (2009).

5. Dehghan M., Saifee M., Hanwate R.: J. Pharm. Sci. Tech. 2, 9 (2010).

6. Patel J.K., Patel R.P., Amin A.F., Patel M.M.: AAPS PharmSciTech. 6, 1 (2005).

7. Miroshnyk I., Mirza S., Sandler N.: Expert Opin. Drug Deliv. 6, 4 (2009).

8. Ghadi R., Ghuge A., Ghumre S., Waghmare N., Kadam V.J.: Indo Am. J. Pharm. Res. 4, 07 (2014).

9. Cheney M.L., Weyna D.R., Shan N., Hanna M., Wojtas L., Zaworotko M.J.: Cryst. Growth. Des. 10, 10 (2010).

10. Yadav S., Gupta P.C., Sharma N., Kumar J.: Int. J. Pharm. Chem. Biol. Sci. 5, 2 (2015).

11. Minhas M.U., Ahmad M., Ali L., Sohail M.: DARU J. Pharm. Sci. 21, 1 (2013).

12. Steed J.W.: Trends Pharmacol. Sci. 34, 3 (2013).

13. Sarfraz R.M., Ahmad M., Mahmood A., Minhas M.U., Yaqoob A.: Adv. Polym. Tech. (2015).

14. Hafeezullah K., Mahmood A., Maheen S., Sarfraz R.M., Yuchi A. et al.: Lat. Am. J. Pharm. 33, 4 (2014).

15. Tabrizi A., Ayhan F., Ayhan H.: Hacettepe J. Biol. Chem. 37, 3 (2009).

16. Lokhande A., Mishra S., Kulkarni R., Naik J.: Int. J. Pharm. Pharm. Sci. 5 (2013).

17. Diyya A.S.M., Kumar V.R.: Int. J. Pharm. Res. Health Sci. 3, 2 (2015).

18. Behera B., Sahoo S., Dhal S., Barik B., Gupta B.: Trop. J. Pharm. Res. 7, 1 (2008).

19. Stuart B.: Infrared Spectroscopy: Fundamental and Applications, John Wiley \& Sons, Ltd, 2004.

20. Mahajan H.S., Dhamne M.R., Gattani S.G., Rasal A.D., Shaikh H.T.: Int. J. Pharm. Sci. Nanotechnol. 3, 4 (2011).

21. Shewale R., Thorat A., Jagtap R., Doijad R.: World J. Pharm. Pharm. Sci. 5, 9 (2016).

22. Pandey N.K., Sehal H.R., Garg V., Gaur T., Kumar B. et al.: AAPS PharmSciTech. (2017).

23. Aulton M.: The science of dosage form design, Churchil Livinstone, London 2008.

24. Gupta V., Mutalik S., Patel M., Jani G.: Acta Pharm. 57, 2 (2007). 
25. Parrot E. Pharmaceutical technology (Fundamental pharmaceutics). pp. 82-6 Minneapolis, Burgess Publishing Company, Minneapolis 1970.

26. Audu M., Umale A.M., Chinnedu I.E: Asian Pac. J. Trop. Medi. 3, 6 (2010).

27. Fiese E., Hagan T. Theory and practice of industry pharmacy. 3rd ed. Bombay: Varghese Publ House; 1987. 171-94 p.

28. Saleh MA., Mohammed SA., Abdullah EC., Hashim LA: Adv Mater Res. 701 (2013).

29. Dash R.N., Mohammed H., Humaira T., Ramesh D.: Saudi Pharm. J. 23, 5 (2015).

30. Nie S., Zhang S., Pan W., Liu Y: Drug Dev. Ind. Pharm. 37, 5 (2011).

31. Mcnamara D.P., Childs S.L., Giordano J., Iarriccio A., Cassidy J. et al.: Pharm. Res. 23, 8 (2006).
32. Jamzad S., Fassihi R.: AAPS PharmSciTech. 7, 2 (2006).

33. Ammar H., Salama H., Ghorab M., El-Nahhas S., Elmotasem H.: Curr. Drug Deliv. 3, 3 (2006).

34. Li Z., Yang B-S., Jiang M., Eriksson M., Spinelli E. et al.: Org. Process Res. Dev. 13, 6 (2009).

35. Mandal U., Gowda V.K., Ghosh A., Selvan P.S., Solomon W.S., Pal T.: Asian J. Chem. 20, 4 (2008).

36. Sanphui P., Goud N.R., Khandavilli U.R., Nangia A.: Cryst. Growth Des. 11, 9 (2011).

37. Song J-X., Yan Y., Yao J., Chen J-M., Lu T-B.: Cryst. Growth Des. 14, 6 (2014).

Received: 27.03.2018 